\title{
THE CONTRIBUTION OF RADAR REMOTE SENSING VIA SENTINEL-1 DATA AND PHOTO-INTERPRETATION BY GOOGLE EARTH IMAGES FOR WETLAND MAPPING
}

\author{
M. Benchelha ${ }^{1}$, F. Benzha ${ }^{1}$, H. Rhinane ${ }^{1}$, A. Zilali ${ }^{2}$ \\ ${ }^{1}$ Geosciences Laboratory, Faculty of Science Ain Chock, Km 8 El Jadida Road, B.P 5366 Maarif Casablanca 20100, Morocco; \\ benchelha.doc@gmail.com ; benzhafatiha@yahoo.fr ; h.rhinane@gmail.com \\ ${ }^{2}$ Mohammadia School of Engineers, Water and Natural Resources Analysis and Modeling Team (AMERN), Ibn Sina Road, \\ B.P 765, Agdal Rabat 10090 MOROCCO; zilali.abdessamad@gmail.com
}

Commission 4, WG 7

KEY WORDS: SAR, Sentinel A1, Polarization, SNAP, Wetland, Benslimane

\begin{abstract}
Wetlands are considered as sensitive ecosystems exposed and threatened by climate change and the urbanization of natural environments. In the purpose of managing these sensitive areas and conservatizing their biodiversity, remote sensing is an efficient way to track environmental variables over large areas as wetlands. However, when it comes to the study of hydrologic dynamics, high temporal and spatial resolutions are essential. Since the access to optical satellite imagery is restrictive because of the large cloud cover that masks the ground, radar sensors that are working in the microwave field, are particularly suited to the characterization of hydrological dynamics due to the sensitivity of their measurements in the presence of water, regardless of the vegetation in place. Recently, radar remote sensing has experienced a real revolution with the launch of the Sentinel-1A satellite in 2014, followed by its twin Sentinel-1B two years later by the European Space Agency as part of the Copernicus program. These sensors acquire C-band data $(\lambda=5.6 \mathrm{~cm})$ with a temporal resolution of 12 days by satellite and their distribution is open and free. This article aims to assess the potential of Sentinel A1 SAR data for wetland mapping in the city of Benslimane (Central Morocco). The first part is explaining the methodology for mapping water surfaces. We identified a confusion of the C-band radar response of water surfaces and that of certain bare soils. We then showed that the $\mathrm{VH}$ polarization is the most suitable for the mapping of water surfaces, comparing four methods of detecting areas in water. It. The second part is discussing the use of unsupervised methods without a priori data demonstrating that the methods taking into account the spatial neighborhood give better results. Temporal filtering has been developed and has made it possible to improve detection and to overcome confusion between bare soil and permanent water surfaces. Water surfaces larger than 0.5 ha are at $80 \%$ detected. Classification was performed using the SVM (Support Vector Machine) algorithm. This latter information was then implemented into the thematic map derived from SPOT-4 images to obtain the final weltands map.
\end{abstract}

\section{INTRODUCTION}

Wetlands have been of strong ecological interest for several years because of their biological, hydrological and biogeochemical functions (Mignot 2005),(Barnaud et Fustec 2007),(Kyle et al. 2004). These environments are therefore at the heart of issues. Management for local communities and natural environment management organizations. The first measures for the preservation of these environments were aimed at their heritage (Alphandéry et Pinton 2007).

The use of optical images is mainly conditioned by the extent of cloud cover. The use of data from RADAR imagery overcomes this problem, with the possibility of acquiring data night and day, without the signal amplitude being significantly disturbed by atmospheric conditions.

A Synthetic Aperture RADAR (SAR) is an active sensor (airborne or satellite) with oblique sighting, which emits an electromagnetic signal continuously in a specific wavelength (microwave range).

Unlike optical sensors, SAR generate their own energy source and the sensor receives backscattered (transmitted) energy from the target on the ground. The measurement of the reflected signal allows to evaluate various geometric and physical properties of the imaged surfaces, such as the roughness, the type of material and the moisture content. The characteristics of the imaged surface determine the backscatter coefficient of the wave, and therefore the level of energy received in return by the RADAR sensor. Since this energy is evaluated for a specific electromagnetic wavelength, the RADAR images are in grayscale. Forests generally appear in a light shade, with rather high and consistent levels of gray. Grasslands, which are smooth surfaces, appear darker, as does a little agitated body of water.

Detecting and characterizing wetlands, which may be vegetated, can be tricky in optical remote sensing, with possible confusion with other land use classes. Synthetic Aperture RADAR (SAR) images are for their part very suitable for the study of these wetlands, since the intensity of the backscattered signal strongly depends on the dielectric constant of the target (which describes the capacitance of a object to interact with the electromagnetic wave), a physical quantity which takes on very high characteristic values for water surfaces (Hostache, Puech, et Raclot 2007).In summary, the characteristics of the signal backscattered to the SAR from a wetland depend essentially on : 
- The wave length, polarization and angle of incidence of the transmitted wave;

- $\quad$ The roughness of the ground;

- The vegetation biomass;

- The dielectric properties of soil and vegetation;

- The presence or absence of free water on the ground (flooding).

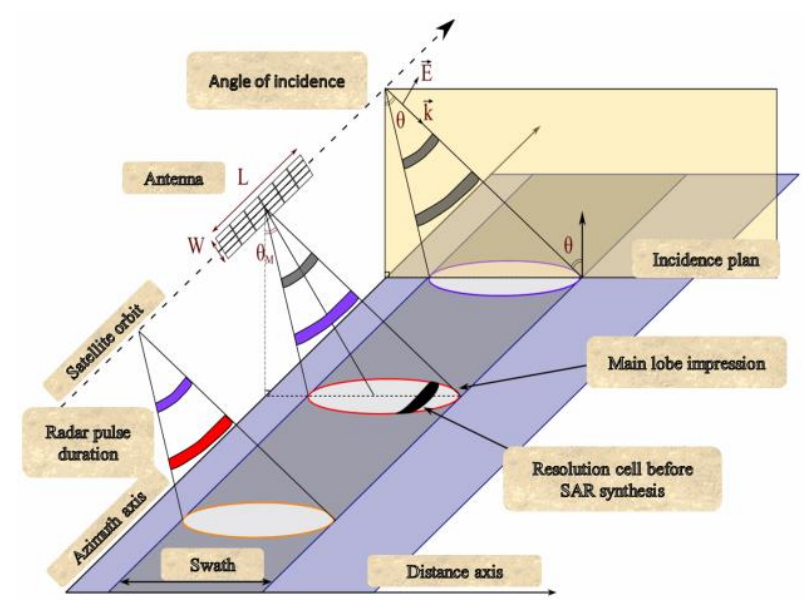

Figure 1. Radar acquisition geometry for Stripmap mode (Lardeux 2008)

The choice of the type of SAR sensor, and the associated polarization properties, is essential in order to distinguish wetlands from other land use classes, and to discriminate the different types of wetlands within the same ecosystem.

The interactions between microwaves and wetlands covered by different types of vegetation are summarized into two types: woody or non woody vegetation (Figure 2).

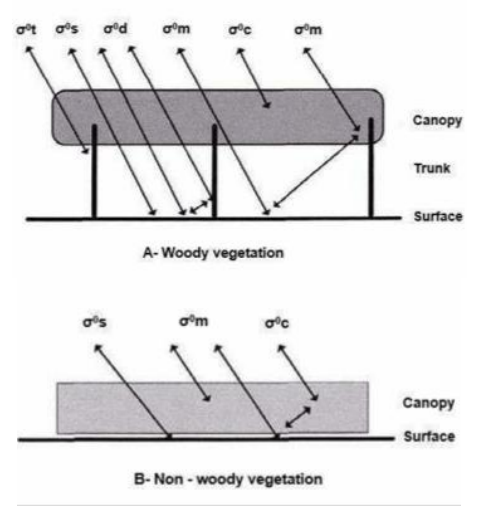

Figure 2. Backscattering sources for a vegetated wetland (Catry et al. 2016).

In the case of (A) tree vegetation and (B) herbaceous vegetation. We distinguish the following coefficients:

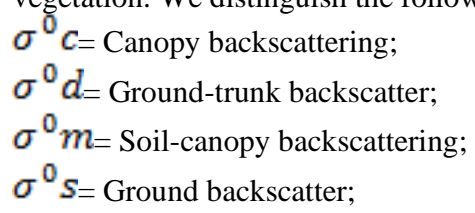

$\sigma^{0} t=$ backscattering of the trunk (Wang et al. 1995).

Generally, the presence of water under the canopy tends to increase the total backscattering because of a double-rebound effect on the vertical structures of tree vegetation, in particular for L-band SAR where water under forest will appear in white on the images. It reduces total backscattering for herbaceous wetlands.

In literature, (Catry et al. 2016) recommended using RADAR remote sensing properties and techniques to characterize different types of wetlands (Table1).

\begin{tabular}{|c|c|c|c|c|c|}
\hline $\begin{array}{l}\text { SAR: } \\
\text { physical } \\
\text { quantities }\end{array}$ & Open water & $\begin{array}{l}\text { Herbaceous } \\
\text { and humid } \\
\text { areas }\end{array}$ & $\begin{array}{l}\text { Wetlands and } \\
\text { forests }\end{array}$ & $\begin{array}{l}\text { Herbaceous vs. } \\
\text { Wetlands and } \\
\text { forests }\end{array}$ & Water height \\
\hline Wave length & $\mathrm{x}$ & $\mathrm{C}$ & $\mathrm{L}$ or $\mathrm{C}+\mathrm{L}$ & $\mathrm{C}+\mathrm{L}$ & - \\
\hline $\begin{array}{l}\text { Polarization } \\
\text { Angle of } \\
\text { incidence }\end{array}$ & vV & $\mathrm{HH}$ & VV or $\mathrm{HH}$ & $\begin{array}{l}\mathrm{VH} \text { or } \mathrm{HV} \text { or } \\
\text { combination }\end{array}$ & $\begin{array}{l}\mathrm{HH}, \mathrm{VH} \text { or } \\
\mathrm{HV}\end{array}$ \\
\hline \multicolumn{6}{|c|}{ SAR: Measurement techniques } \\
\hline $\begin{array}{l}\text { Backscattered } \\
\text { intensity }\end{array}$ & $\begin{array}{l}\text { Threshold, } \\
\text { Texture, and } \\
\text { Segmentation }\end{array}$ & \begin{tabular}{|l|} 
Multi- \\
temporal \\
approach
\end{tabular} & $\begin{array}{l}\text { Multi- } \\
\text { temporal and } \\
\text { multi-impact } \\
\text { approach }\end{array}$ & $\begin{array}{l}\text { Seasonal } \\
\text { approach }\end{array}$ & - \\
\hline InSAR & - & - & - & - & \begin{tabular}{|l|} 
High \\
temporal \\
repetitiveness
\end{tabular} \\
\hline Altimetry & - & - & - & - & $\begin{array}{l}\text { Direct data or } \\
\text { combination } \\
\text { with InSAR } \\
\text { or backscatter }\end{array}$ \\
\hline Polarimetry & $L_{1}$ & - & - & \begin{tabular}{|l|}
$\mathrm{HH}+\mathrm{HH} / \mathrm{HV}$ \\
Freeman- \\
Dourdan and \\
Claude Poirier \\
decompositions
\end{tabular} & $\begin{array}{l}\text { Multi- } \\
\text { temporal } \\
\text { approach or } \\
\text { alpha angle }\end{array}$ \\
\hline \multicolumn{6}{|c|}{ Recommended sensors (Free data) } \\
\hline & Sentinel 1 & Sentinel 1 & $\begin{array}{l}\text { Sentinel1, } \\
\text { ALOS- } \\
\text { PALSAR }\end{array}$ & $\begin{array}{l}\text { Sentinel1, } \\
\text { ALOS- } \\
\text { PALSAR }\end{array}$ & $\begin{array}{l}\text { Sentinel1, } \\
\text { ALOS- } \\
\text { PALSAR }\end{array}$ \\
\hline
\end{tabular}

Table 1. Recommendations for the use of SAR for the characterization of the different types of wetlands in the Amazonian context (Catry et al. 2016).

From 2014, Sentinel-1 data is acquired. The contribution of a year of acquisition could not be assessed until 2016. There are therefore few studies on the high temporal radar resolution of the Sentinel A1 satellite. Studies using X-band (Betbeder 2015), (Martinis, Kersten, et Twele 2015),(Pulvirenti et al. 2011) or Cband(Marechal et al. 2012), (Zhao et al. 2014), (Schmitt et Brisco 2013) have shown the interest of using time series to characterize wetlands.

\section{METHODOLOGY}

In order to assess the potential of radar images for wetland discrimination, we are looking for a method that simply estimates the separability of the Water and Other classes from a single polarization image. We assume that the two classes can be separated by a threshold of $\sigma 0$.

To assess this separability, it is necessary to have samples of the Water and Other classes (forests, cultivated land, urbanized area and bare soil) representing the "ground truth". The process for obtaining learning areas (Samples) from field visits to locate wetlands (Dayas) at the scale of the study area on the one hand. And on the other hand, the zones are delimited on the basis of the optical images. The results are stored in a polygon-type shapefile.

The methodology adopted is based on the identification of the limits of the dayas by processing SAR data with the validation 
of the results by photo-interpretation techniques through the use of Google Earth images.

To identify wetlands from satellite images, there are a number of methods of detecting water from single polarization radar images. We can classify these methods according to 4 families:

- The automatic methods or unsupervised methods based on the numeric subdivision of pixels, which results are confusing different classes and land occupation;

- Simple supervised methods such as supervised thresholding; identifying spectrally similar areas by calculating the average of pixels;

- $\quad$ Supervised methods with region growth algorithm such as supervised thresholding by hysteresis, which adds more information to the spectral signature with statistics and probabilities;

- Textural analysis methods such as proposed by (Haralick, Shanmugam, et Dinstein 1973), which is object oriented and allows to regroup homogenous pixels with same properties and signature.

The comparison of the four methods will be performed on four Sentinel-1 single polarization VH images, due to their better ability to distinguish water. The Sentinel-1 image of January 16, 2019 in VH polarization was used for this study because it is a date with little ambiguity with the presence of urbanized areas and agricultural land. The acquisition of April 01, 2018 was also chosen because it is a date that contains a lot of confusion. The comparison of two images with the third image acquired in February 21, 2016 is characterized by moderate ambiguity. These three images will allow us to study the robustness of the methods in the ideal case where the confusion between classes is low but also in the case of strong confusion. The results of classifying three images using four classification methods are presented in the results and discussion section.

We therefore worked with the three Sentinel 1 images. The main characteristics of the images available for this study as well as their acquisition dates are given in the following table:

\begin{tabular}{|l|l|l|}
\hline Fashion & Wide swath interferometric IW \\
\hline Polarization & VV/VH \\
\hline Footprint of images & $250 \times 200 \mathrm{~km}$ \\
\hline Orbit orientation & Ascending \\
\hline $\begin{array}{l}\text { Angles of incidence on the wetland right-of- } \\
\text { way }\end{array}$ & $36-42^{\circ}$ \\
\hline Noise-Equivalent Sigma-Zero & $-22 \mathrm{~dB}$ & GRD \\
\hline Data type & SLC & $20^{*} 22 \mathrm{~m}$ \\
\hline Spatial resolution (azimuth range) & $2,7 \mathrm{à} 3,5 * 22 \mathrm{~m}$ & $10 \_10 \mathrm{~m}$ \\
\hline Pixel size & $2,3 \_14,1 \mathrm{~m}$ & 4.9 \\
\hline Number of views & 1 & \\
\hline Date of acquisitions & $\begin{array}{l}\text { February } 21,2016 \\
\text { April } 01,2018 \\
\text { January| } 16,2019\end{array}$ \\
\hline
\end{tabular}

Table 2. Characteristics of Sentinel-1 images (Aulard-Macler et al. 2011)

Sentinel- 1 data are mainly acquired in $C$ band $(\lambda=5.6 \mathrm{~cm})$ and with the VV / VH configuration of the Interferometric Wide swath (IW) mode on Moroccan territory.

Before beginning the classification of the SAR images, a first phase is necessary to carry out the preprocessing of the Sentinel A1 Radar images, the steps of these processes are illustrated in the following diagram:
The preprocessing prior to the analysis of the radar images are: Calibration, geocoding used, as well as filtering. The processing steps are summarized in figure 3 .

To classify the pixels of the radar image, we make a learning Shapefiles. This file will be used to carry out the supervised classifications for several algorithms used in this study.

SAR pretreatment process

\begin{tabular}{|c|c|c|}
\hline $\begin{array}{l}\text { Automatic image } \\
\text { download (SLC } \\
\text { from S1) }\end{array}$ & $\begin{array}{l}\text { Automatic } \\
\text { download of } \\
\text { orbit files }\end{array}$ & $\begin{array}{c}\text { Preparation of } \\
\text { DEM }\end{array}$ \\
\hline \multicolumn{3}{|c|}{ Import SLC data } \\
\hline \multicolumn{3}{|c|}{$\begin{array}{l}\text { Pretreatment : } \\
\text { - Radiometric calibration } \\
\text { - Thermal noise removal } \\
\text { - Topsar deburst } \\
\text { - Lalti-look } \\
\text { - Correction ground } \\
\text { - Speckle filter }: \text { Lee }\end{array}$} \\
\hline \multicolumn{3}{|c|}{ GRD products } \\
\hline \multicolumn{3}{|c|}{ Co-registration of images and stacking } \\
\hline \multicolumn{3}{|c|}{ Application of a multitemporal filter } \\
\hline $\begin{array}{r}\text { Calculates } \\
\text { Minimum / Ma }\end{array}$ & $\begin{array}{l}\text { stics for the stac } \\
\text { aum / Average / } \\
\text { efficient of varia }\end{array}$ & $\begin{array}{l}\text { and VH): } \\
\text { rd deviation / }\end{array}$ \\
\hline
\end{tabular}

Figure 3. SAR pre-treatment process before classification

The permanent water polygons and the permanent emergent zones were drawn by photo-interpretation. The Water class polygons have been delineated on optical imagery, which is assumed to be closer to reality. The polygons of the other class were drawn by photo-interpretation using all the radar images: areas with low backscattering (which could be mistaken for water) and were systematically taken into account.

The detection of areas in water by radar remote sensing is mainly based on centimeter wavelengths, which is an electromagnetic wave that has a specular reflection on open water. Water is therefore characterized by low backscattering, while land surfaces backscatter part of the emitted wave towards the sensor. Accordingly, the identification process of wetlands in Benslimane case study had used SVM classification.

First, in order to estimate the efficiency of extraction and identification of wetlands in the town of Benslimane from SAR data, an SVM classification was applied on the coherence matrix (T) for the three polarimetry images used (two images in pairs).

SVM is a supervised learning classification method, which was introduced in the 1990 by(Vapnik 1999). This method relies on the existence of a linear classifier in an appropriate space. It is based on the use of a kernel function. The goal of a kernel function is to weight observations relative to a reference point so that the closer an observation is to the reference, the greater 
its weight (Mathieu-Dupas 2010). It therefore allows optimal data separation.
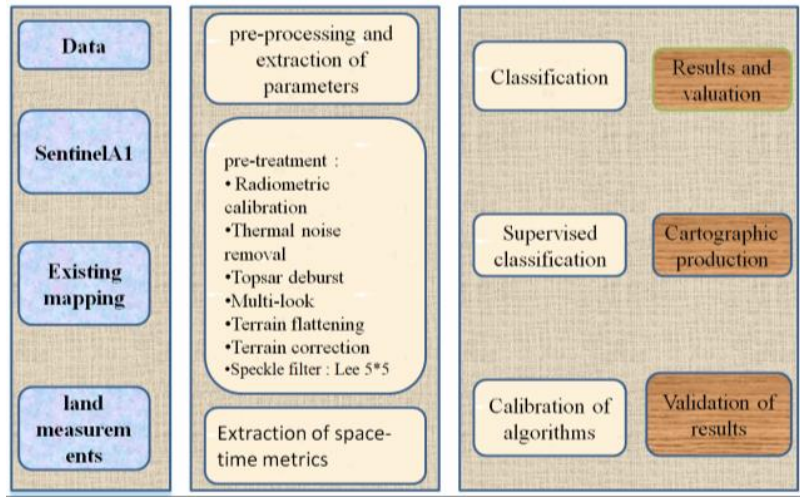

Figure 4. Sentinel 1 SAR image processing methodology

This entire image processing process was performed using Sentinel Application Platform SNAP software, developed by Brockmann Consult, SkyWatch and C-S of the Space Agency.

\section{STUDY AREA}

The study was carried out in the municipality of Benslimane (Figure 5), capital of the agricultural province, bounded by the municipality of Ain Tizgha to the east and north, the municipality of Ziaida to the south and the municipality of Oulad Yahya Louta in the West. In the north-west, the high altitudes range from 175 to about $390 \mathrm{~m}$. The area of the municipality of Benslimane is about $72 \mathrm{~km} 2$, the polar coordinates are $33^{\circ} 36 \mathrm{~N}$ latitude and $7^{\circ} 06 \mathrm{~W}$ longitude, the Lambert coordinates averages are $\mathrm{x}=342000, \mathrm{y}=336000$. The town of Benslimane has a population of approximately 57101 inhabitants (General census of population RGPH 2014).

\section{$>$ Climate}

The city of Benslimane is characterized by a dry climate with alternating cold and hot continental type (Benchelha, Benzha, et Rhinane 2019).

\section{$>$ Temperature}

Benslimane's annual average temperatures are $23.7{ }^{\circ} \mathrm{C}$ for the maximum and $10.3{ }^{\circ} \mathrm{C}$ for the minimum. As one travels away from the Atlantic coast, there are considerable variations. The average annual temperature of the coastal zone is $17.5^{\circ} \mathrm{C}$, with a mean temperature not exceeding $32{ }^{\circ} \mathrm{C}$. The low interior plateaus show very high thermal amplitudes, but without sudden variations. The average annual temperature on these plateaus is $18.5^{\circ} \mathrm{C}$, with a high of $40^{\circ} \mathrm{C}$. (Benchelha, Benzha, et Rhinane 2019).

\section{$>$ Rainfall}

In the province, the average annual rainfall recorded is $350 \mathrm{~mm}$. For the Feddan Taba and Malleh Dam pluviometry stations, the average annual precipitation measured for the period 19892019 is approximately $363 \mathrm{~mm}$. The average monthly distribution of rainfall suggests the presence of two distinct seasons: the wet season from October to May, during which nearly all rainy episodes occurred ( 86 to $92 \%$ of the annual rainfall); the dry season from May to September, with just 8 to
$14 \%$ of the annual rainfall (Benchelha, Benzha, et Rhinane 2019).

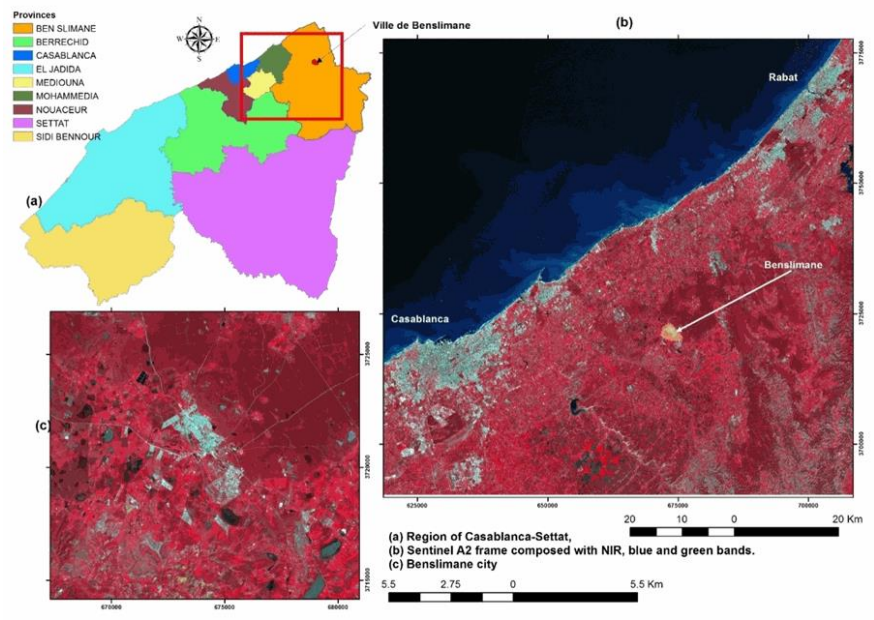

Figure 5. Location of the study area on a Sentinel A2 background image

\section{RESULTS AND DISCUSSION}

Analysis and monitoring by Google Earth images shows the degradation of the wetlands "Dayas" between May 2003 and January 2019 (Figure 6) which are located in the western part of the town of Benslimane. Based on this analysis, several dayas have disappeared and replaced by urbanized areas. The Google Earth images taken between 2003 and 2013 shows that the dayas remain wet for three months after the precipitation recorded during the months of January, February and March.

From 2013, the development of the city is moving towards the West, and we note the filling of certain dayas which favors a change of flow direction, which influences the water connection between the depressions. (Figure 6, image dated 01/4/2018). From January 2019, and after the validation of the development plan of Benslimane city, several subdivisions are being developed by backfilling the depressions occupied by the dayas, for this purpose several connecting water bodies supplying the dayas have disappeared. 

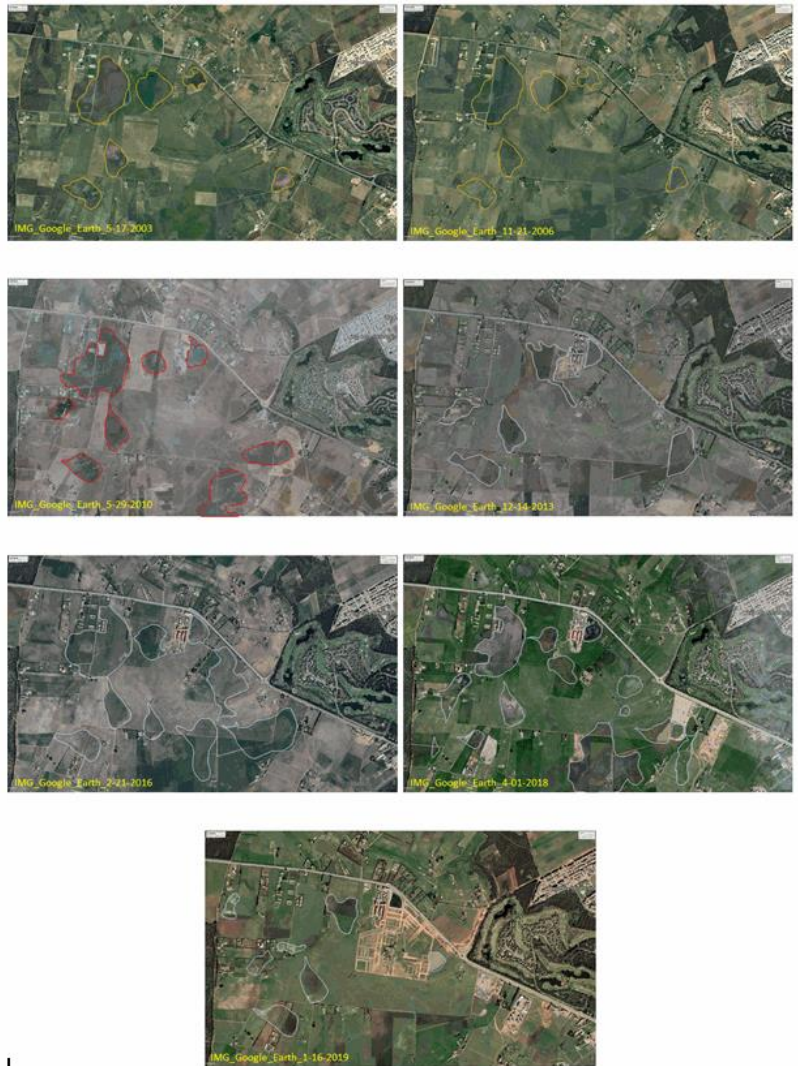

Figure 6. Temporal and spatial follow-up of the evolution of the urban fabric of the city of Benslimane on the wetlands (dayas).

Interpretation of Google Earth images presents an element of identifying daya in order to create learning zones. These zones are used in the phase of the supervised classification of SAR images by the algorithms chosen in particular the classification by the SVM and Random Forest methods.

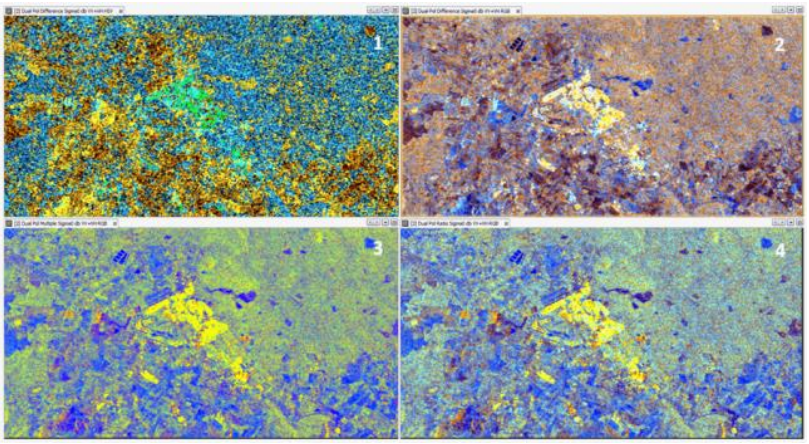

Figure 7. Color composition for several combination of polarization modes $(\mathrm{VV}, \mathrm{VH})$ that shows identification of wetlands and soil moisture separately.

(1) composition : Dual Pol Différence Sigma0 db VV+VH HSV ; (2) composition : Dual Pol Différence Sigma0 db VV+VH HSV ;

(3) composition : Dual Pol Différence Sigma0 db VV+VH HSV;

(4) composition : Dual Pol Différence Sigma0 db VV+VH HSV ;

The colored compositions used in Figure 7 show both wetlands (focus of this article) and soil moisture to separate the two categories,
The Radar images detect, in addition to the dayas of the city, the wet ground, after improving and optimizing the algorithms of several classification methods.

\section{$>$ Classification by the Random forest method}

The Random Forest classification method has the ability to identify and separate the different areas occupied by open water or water from those occupied by other areas (urbanized areas, bare soils and cultivated land without forgetting the forest cover This classification method was chosen due to its fast execution and good quality of its results, and it also gives a classification confidence index for each pixel.

To evaluate the classification by the Random Forest method, the algorithm of this method requires several learning points for its operation. All the points given to the classification algorithm are a total of 47 points, namely: 5 points for the forest class, 21 points for the Open water class, 15 points for the Water class with vegetation and 6 points for both classes: Agricultural land and bare soil. The points were randomly separated to obtain learning points and points for validation. In the validation phase of the classification, the method algorithm makes a comparison based on the analysis of the confusion matrix to calculate the classification precisions.

Sentinel-1's preferred polarimetric configuration (VV / VH) provides precision to separate Water classes at $79 \%$.

The following figure shows the wetlands of Benslimane by the Random Forest classification algorithm. The areas in dark blue correspond to the dayas of the study area.

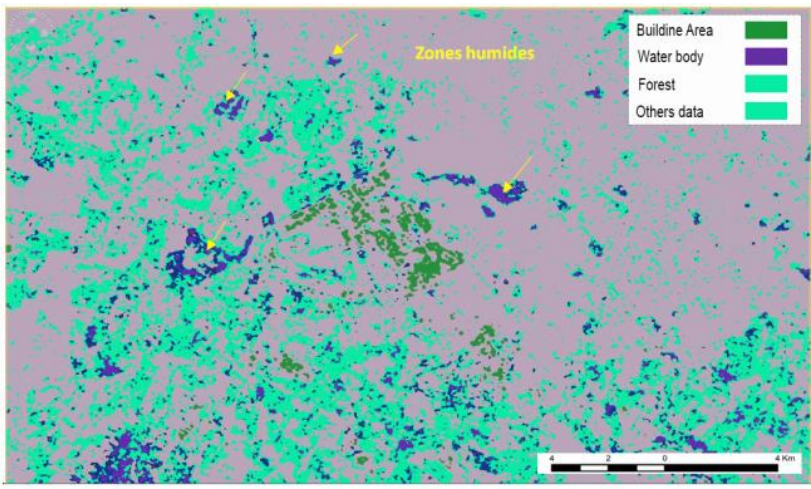

Figure 8. Random Forest classification results

\section{$>$ Classification of the temporal series image with the algorithm (SVM)}

Among kernel methods, inspired by Vapnik's statistical theory of learning, SVMs are the most well-known form. SVM is a supervised learning binary classification method, it was introduced by (Cortes et Vapnik 1995). This method is therefore a recent alternative for classification. This method relies on the existence of a linear classifier in an appropriate space. Since this is a two-class classification problem, this method uses a training dataset to learn the parameters of the model. It is based on the use of so-called kernel functions which allow optimal data separation. 


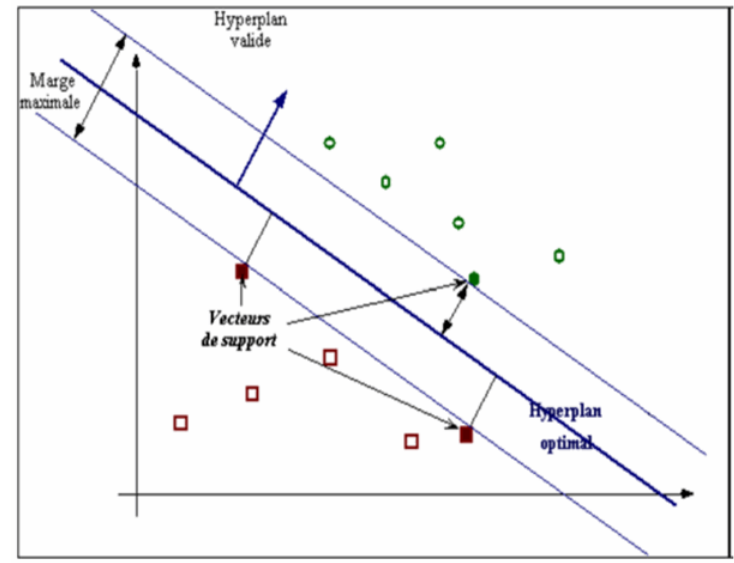

Figure 9. Principe de la classification SVM (Mohamadally et Fomani 2006)

The goal of SVM is to find a classifier that will separate the data and maximize the distance between these two classes. With SVM, this classifier is a linear classifier called a hyperplane. The closest points, which alone are used for the determination of the hyperplane, are called support vectors

Despite the existence of multitude valid hyperplanes, the remarkable property of SVM makes it the most optimal for our case study, because of it passes "in the middle" of the points of the two classes of examples. Indeed, even if we suppose an example that has not been described perfectly, a small variation will not modify its classification if its distance from the hyperplane is large. Formally, this amounts to looking for a hyperplane whose minimum distance to the learning examples is maximum. This distance is called the "margin" between the hyperplane and the examples. The optimal splitter hyperplane is the one that maximizes the margin. Since we are trying to maximize this margin, SVM can be adapted to become a nonlinear classifier using Nonlinear Kernels. Although SVM is a binary classifier in its simplest form, it can function as a multiclass classifier by combining multiple binary SVM classifiers (creating a binary classifier for each possible pair of classes).

The ENVI Classic implementation of SVM uses the pairwise classification strategy for multiclass classification. The result of the SVM classification corresponds to the decision values of each pixel for each class, which are used for the probability estimates. The probability values, stored in ENVI Classic as ruler images, represent a "true" probability in the sense that each probability falls in the range 0 to 1 and the sum of these values for each pixel is equal to 1. ENVI Classic performs the classification by selecting the highest probability. An optional threshold is used to report pixels for which all probability values are less than the unclassified threshold. (Kyle et al. 2004).

The classification check is made on the basis of a sample of pixels verified in the field. Sampling is done on the whole image either with a random spatial distribution and a random class distribution, or with a spatial distribution based on the data available on the ground.

The number of pixels in the sample is 47 points depending on the availability of ground truth data. Classification assessment is provided by the confusion matrix or contingency table. It is obtained by comparing the classified data with reference data which are different from those used to carry out the classification. Each column in the matrix represents the number of occurrences of an estimated class, while each row represents the number of occurrences of an actual class (or reference).

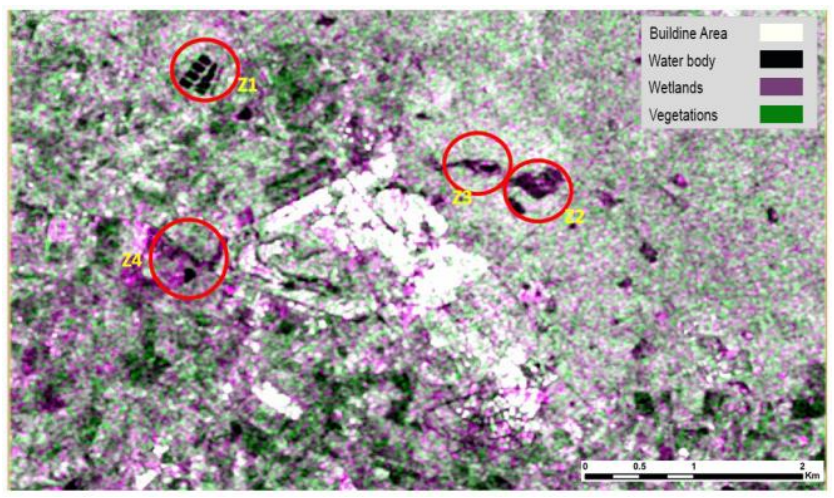

Figure 10. Wetlands identified with Support Vector Machine classification

Verifying and comparing with the actual state in the field, we can validate the results obtained in the map.

Zone 1 detected corresponds to the wastewater treatment plant which has been correctly removed, this zone benefits from its location far from the other classes introduced. This characteristic increases the precision of separating this zone from other zones, particularly the forest, the urbanized zone and the cultivated land;

Zone 2 and 3 correspond to three dayas which are located in a forest environment. This area was also highlighted in the SVM classification despite the existence of dry areas that surround the two dayas. This result is due to the ability of radar images to detect soil moisture;

We note the existence of classes of bare and built soil, as well as small dayas. The image in zone 4 shows the areas occupied by water despite the presence of the frame and bare soil. The last two are similarity classes.

\section{CONCLUSION}

The work presented in this article shows that it is possible to delineate wetlands using $\mathrm{C}$-band radar images acquired in partial VV / VH polarization.

Fully polarimetric radar images were used to simulate radar databases in partial polarimetry configuration. The ability of these different databases to discriminate between open water, water with vegetation as well as water is bare soil and buildings. This identification was assessed using a supervised Random Forest classification and SVM.

We can interpret from the wetland mapping of Benslimane that the wetlands (dayas) are detectable and well separable from other types of land use, even if confusion may occurs between the classes of dayas, built and bare ground, it varies from 10 to $35 \%$ according to the polar metric configurations. A more indepth study could be carried out to better understand these results. Also, using a low incidence angle improves the classification results, which is in agreement with the literature. 
Still, the VV/VH configuration is less sensitive to this phenomenon.

To conclude, the optimization of wetlands mapping has been possible to $70 \%$ with the combination of Sentinel-1 C-band SAR instruments in dual polarisation $(\mathrm{VV}+\mathrm{VH})$ and $\mathrm{SVM}$ classification.

\section{REFERENCES}

Alphandéry, Pierre, et Florence Pinton. 2007. « Des Znieff à Natura 2000, connaissances naturalistes et conservation de la biodiversité. L'exemple icaunois ». Revue scientifique Bourgogne Nature 6: 59- 75.

Aulard-Macler, M., R. Barstow, D. Ramsbottom, et P. Lim. 2011. «Sentinel-1 product definition». Document Reference MPC-0240.

Barnaud, Geneviève, et Éliane Fustec. 2007. Conserver les milieux humides: pourquoi? comment? Educagri editions.

Benchelha, M, F Benzha, et H Rhinane. 2019. «OBJECT BASED "DAYAS “ CLASSIFICATION USING SENTINEL A-2 SATELLITE IMAGERY CASE STUDY CITY OF BENSLIMANE $», 7$.

Betbeder, Julie. 2015. « Evaluation des données de télédétection pour l'identification et la caractérisation des continuités écologiques ». PhD Thesis, Université Rennes 2.

Catry, Thibault, Zhichao Li, Emmanuel Roux, Vincent Herbreteau, Christophe Révillion, et Nadine Dessay. 2016. «Fusion of SAR and optical imagery for studuing the ecoepidemiology of vector-borne diseases in tropical countries ». In 2016 European Space Agency Living Planet Symposium.

Cortes, Corinna, et Vladimir Vapnik. 1995. « Support-vector networks ». Machine learning 20 (3): 273- 97.

Haralick, Robert M., Karthikeyan Shanmugam, et Its' Hak Dinstein. 1973. «Textural features for image classification». IEEE Transactions on systems, man, and cybernetics, $\mathrm{n}^{\circ} 6$ : 610- 21.

Hostache, Renaud, Christian Puech, et Damien Raclot. 2007. "Caractérisation spatiale de l'aléa inondation à partir d'images satellites RADAR ». Cybergeo: European Journal of Geography.

Kyle, Gerard, Alan Graefe, Robert Manning, et James Bacon. 2004. "Effects of place attachment on users' perceptions of social and environmental conditions in a natural setting ». Journal of environmental psychology 24 (2): 213- 25.

Lardeux, Cédric. 2008. «Apport des données radar polarimétriques pour la cartographie en milieu tropical ». $\mathrm{PhD}$ Thesis, Université Paris-Est.

Marechal, Cécile, Eric Pottier, Laurence Hubert-Moy, et Sebastien Rapinel. 2012. «One year wetland survey investigations from quad-pol RADARSAT-2 time-series SAR images ». Canadian Journal of Remote Sensing 38 (3): 240- 52 .
Martinis, Sandro, Jens Kersten, et André Twele. 2015. « A fully automated TerraSAR-X based flood service ». ISPRS Journal of Photogrammetry and Remote Sensing 104: 203- 12.

Mathieu-Dupas, Eve. 2010. «Algorithme des k plus proches voisins pondérés et application en diagnostic ». In 42èmes Journées de Statistique.

Mignot, J. F. 2005. «L'inventaire des zones humides dans les SAGE ». Guide méthodologique, Agence de l'eau LoireBretagne.

Mohamadally, H., et B. Fomani. 2006. «SVM: Machines a vecteurs de support ou separateurs a vastes marges ». Survey, Versailles St Quentin 16.

Pulvirenti, L., M. Chini, N. Pierdicca, L. Guerriero, et P. Ferrazzoli. 2011. «Flood monitoring using multi-temporal COSMO-SkyMed data: Image segmentation and signature interpretation ». Remote Sensing of Environment 115 (4): 990- 1002.

Schmitt, Andreas, et Brian Brisco. 2013. «Wetland monitoring using the curvelet-based change detection method on polarimetric SAR imagery ». Water 5 (3): 1036- 51.

Vapnik, Vladimir N. 1999. « An overview of statistical learning theory ». IEEE transactions on neural networks 10 (5): 988- 99.

Wang, Y., Frank W. Davis, John M. Melack, Eric S. Kasischke, et Norman L. Christensen Jr. 1995. « The effects of changes in forest biomass on radar backscatter from tree canopies ». Remote Sensing 16 (3): 503- 13.

Zhao, Lingli, Jie Yang, Pingxiang Li, et Liangpei Zhang. 2014. «Seasonal inundation monitoring and vegetation pattern mapping of the Erguna floodplain by means of a RADARSAT2 fully polarimetric time series ». Remote sensing of environment 152: 426- 40. 